The MRT in several digestive compartments of the rabbit was studied in 4 adult female cannulated at the ileum, receiving ad libitum 3 diets, differing mainly in the fibre level (22-40\% NDF). Whole tract and ileo-rectal MRT were simultaneously measured by following the fecal kinetics of 169 ytterbium and ${ }^{141}$ cerium adsorbed onto fibre particles and given orally $(\mathrm{Yb})$ or through the ileal cannula $(\mathrm{Ce})$. The results are shown in table $\mathrm{I}$.

Whatever the diet, the whole tract MRT provided by modelling [Grovum and Williams (1973) $\mathrm{Br} J$ Nutr 30, 313-329] was similar to that obtained algebraically (reference method [Faichney (1975) In: Digestion and metabolism in the ruminant. 227-241]). The increase in the dietary fibre level slightly affected the feed intake (112 to $119 \mathrm{~g} / \mathrm{d}$ ). On the other hand, the $40 \%$ increase in fibre intake (26-44 g NDF/d) led to a $40 \%$ decrease in the whole-tract MRT $(-12 \mathrm{~h})$, originating mainly from a 2-fold reduction of the ileo-rectal MRT. Oro-ileal MRT (mean $5 \mathrm{~h}$ ) was not affected by the dietary fibre incorporation, but MRT in the stomach was significantly longer, therefore involving a shorter MRT in the small intestine.

Thus, dietary fibre mainly affected the rate of passage through the posterior part of the rabbit tract, whereas it remained steady in the anterior part due to a compensation between stomach and small intestine.

\section{Effect of caseinomacropeptide (CMP) on gastric secretion and plasma gut regu- latory peptides in preruminant calves.} $P$ Guilloteau 1, I Le Huërou-Luron 1, JA Chayvialle ${ }^{2}$, R Toullec ${ }^{1}, \mathrm{M}$ Legeas ${ }^{1}$, C Bernard 2, L Roger ${ }^{3}, \mathrm{~F}$ Mendy ${ }^{4}$ ( ${ }^{1}$ INRA, Laboratoire du Jeune Ruminant, 65, rue de Saint-Brieuc, 35042 Rennes Cedex; 2 INSERM, U45, Hôpital Édouard-Herriot, 69374 Lyon Cedex; ${ }^{3}$ Nutrinov, 65, rue de Saint-Brieuc, 35042 Rennes Cedex; 41 , place de Béarn, 92110 Saint-Cloud, France)

Caseinomacropeptide (CMP) is a 64-amino-acid peptide secreted in the stomach as a result of proteolytic enzyme activity on $\kappa$ casein. It is found in 8 or 9 different forms which differ according to their glycosylation at 5 potential sites. When injected by parenteral infusion, it reduces gastric secretion in dogs [Vasilevskaya et a/ (1977) Vopr Pitan 4, 21-24], and gastrin levels in rats [Aleinik et al (1984) Vopr Pitan 2, 47-50], but causes no such reduction in calves [Guilloteau et al (1987) Reprod Nutr Dev 27, 287-288]. Following milk ingestion in calves, CMP enters the duodenum intact, especially during the first postprandial 30 min [Yvon et al (1986) Reprod Nutr Dev 26, 705715]. The purpose of the present study was to check whether the effects of infusion, which had been observed in several species, were similar after ingestion of CMP.

All animals received a milk substitute $(T)$, in which the proteins ( $25 \%$ of dry matter) were exclusively provided by a CMP-free 'whey protein concentrate from hydrochloric acid casein preparation'. The CMP (a preparation containing a mixture of glycosylated and non-glycosylated CMP, slightly contaminated by the 1-23 fragment of $\alpha 1$ casein) was introduced into the $T$ diet as a partial lactose substitute, at 2 different concentrations, ie equal to and 5 times higher than cows' milk CMP (diets CMP 1 and CMP 5). The calves were fed 2 meals per day at $7-h$ intervals, on the basis of 45-55 g DM/kg LW 0.75 .

Total quantities of gastric juices secreted in 24 $h$ and measured in 10 calves did not vary in the presence of CMP (491-525 g per day per $100 \mathrm{~kg}$ LW); pepsine quantities seemed lower with diets CMP 1 and CMP 5 than with diet T; and chymosine quantities seemed lower with diet CMP 1 (NS). During the first and/or the second postprandial hour, the quantities of gastric juice, enzymes and $\mathrm{H}^{+}$secreted were higher with diet $\mathrm{T}$. No such increase occurred during the first $2 \mathrm{~h}$ in the case of diet CMP 1, but only during the first hour in the case of diet CMP 5 (fig 1). At the same time, in the case of diet $T$, meal ingestion induced an increase in plasma levels of digestive regulatory peptides, which were measured in 26 calves by radioimmunoassay using the double antibody technique [Guilloteau et al (1992) In: Nutrition-related endocrine changes in cattle (M Stangassinger, JW Blum, eds), University of Berne, 44-53]. The CCK increase was partially inhibited in the case of diet CMP 1. On the other hand, the somatostatin increase was more pronounced (fig 1). In the case of diet CMP5, these differences were reduced to a large extent, or were non-existent.

In conclusion, when CMP is ingested at a similar rate to that contained in cows' milk, it seems to induce transient postprandial inhibition of gastric secretion, whereas it seems to have little or no effect when ingested at a rate 5 times higher. Digestive regulatory peptides appear to be involved in the regulatory processes. 